\title{
El precio de pasarse al enemigo. ETA, el nacionalismo vasco radical y la figura del traidor ${ }^{1}$
}

\author{
Gaizka FERnÁndez SoldeVILla \\ IES Marqués de Manzanedo (Santoña) \\ gaizka_fernandez@yahoo.es
}

Recibido: 5/5/2013

Aceptado: 10/6/2013

\section{RESUMEN}

En el presente artículo se examina cuál ha sido la reacción de ETA y su entorno civil, la autodenominada "izquierda abertzale", ante las disidencias individuales o colectivas que han juzgado como una traición a la patria vasca. En primer lugar, las escisiones obreristas de ETA (ETA berri y ETA VI Asamblea) en la dictadura franquista. En segundo término, la heterodoxia de Euskadiko Ezkerra durante la Transición y la disolución a principios de los ochenta de un sector de ETA político-militar. Tercero y último, los activistas de ETA militar que han colaborado con la policía o han optado por la reinserción individual. De esta manera, se pretende comprender mejor la cultura política del nacionalismo vasco radical.

Palabras clave: ETA, nacionalismo vasco radical, País Vasco, traición, heterodoxia, cultura política, Yoyes.

\section{The Price of Joining the Enemy. ETA, Basque Radical Nationalism and the Figure of the Traitor}

\begin{abstract}
This article focuses on the reactions of ETA and its civil environment -the so-called "patriotic left"- to dissident groups or individuals it labeled as traitors to the Basque Country: first, ETA's left-wing splits -ETA berri and ETA VI- during the Dictatorship of General Franco. Second, the heterodoxy of Euskadiko Ezkerra in the process of Spain's Transition to democracy and the disintegration of ETA's politicalmilitary wing in the early 1980s. And finally, ETA's military wing activists who ended up collaborating with the police forces or assimilated themselves into society. In the end, this essay aims to reach a better understanding of the political culture of Basque radical nationalists.
\end{abstract}

Key words: ETA, Basque Radical Nationalism, Basque Country, Treason, Heterodoxy, Political Culture, Yoyes.

\section{Referencia normalizada}

Fernández Soldevilla, Gaizka. (2013). "El precio de pasarse al enemigo. ETA, el nacionalismo vasco radical y la figura del traidor". Cuadernos de Historia Contemporánea, Vol.: pp. 89-110.

Sumario: Introducción. 1. Estatutistas. El PNV. 2. Obreristas y españolistas. ETA berri y ETA VI. 3. Vendepatrias y arrepentidos. ETApm, EIA y EE. 4. Infiltrados y confidentes. ETAm I. 5. Desertores. ETAm II. 6. Conclusiones. 7. Referencias bibliográficas.

\footnotetext{
${ }^{1}$ Agradezco a José Luis de la Granja, Raúl López Romo, Jesús Casquete y Barbara van der Leeuw sus valiosas sugerencias para mejorar el texto original, así como a Florencio Domínguez la aportación de diversa documentación y útiles referencias.
} 


\section{Introducción}

Los movimientos nacionalistas (aunque no solo ellos) suelen asentarse sobre mitos históricos que, al entrelazarse, constituyen una narrativa estructurada en forma de tríada. Primero, un pasado glorioso. En segundo término, un presente en decadencia en el que la patria corre peligro de desaparecer. Y, tercero y último, un futuro utópico (eventualmente la secesión territorial). Dicho relato proporciona un diagnóstico de culpabilidad (el agente externo o interno que acabó con la Edad de Oro) y una prescripción (la estrategia para recuperar el paraíso perdido) ${ }^{2}$.

Como toda fábula política, el canon nacionalista está protagonizado por héroes, seres humanos valerosos y excepcionales. En caso de sacrificar su vida por la patria, son elevados a la categoría de mártires. Auténticos símbolos, héroes y mártires sirven para cohesionar a la comunidad y como modelos a imitar. En último extremo, su instrumentalización puede ayudar a legitimar una opción violenta. Ahora bien, como indica Jesús Casquete,

para erigirse en tal, el héroe precisa de una contraparte, de un anti-héroe que encarne el principio del Mal, la impureza, la desgracia y la destrucción con quien se batirá hasta las últimas consecuencias en representación del grupo amenazado. Aunque sólo sea para mantener ocupados a los héroes, una sociedad precisa de villanos ${ }^{3}$.

Con estos mimbres las variantes más radicales del nacionalismo establecen una dicotomía maniquea, una polarización del universo moral entre buenos y malos. No hay término medio: se está con o contra "nosotros". Mas la dualidad se ve un tanto enturbiada cuando hace su aparición un tercer arquetipo: el traidor, es decir, quien ha cambiado de trinchera. Se emplea aquí la perspectiva del propio movimiento, es decir, lo que hace la defección real es que sea percibida de ese modo. En su Tratado sobre la tolerancia (1767) Voltaire aseveraba que "sabido es el implacable odio que sienten todos los sectarios por los que abandonan su secta" 4 . Y es que un amigo que se pasa al enemigo se transforma no solo en un nuevo adversario, sino en el peor de todos. Por un lado, de su alevosía cabe esperar un daño directo a la causa, como la delación de sus excompañeros. Por otro, sobre todo si se trata de un antiguo héroe devenido en anti-héroe, hay serias implicaciones a nivel simbólico y propagandístico. El judas formó parte del "nosotros", pero ahora ha pasado al bando del "ellos" por voluntad propia, transitando a veces por una zona gris intermedia. Su apostasía acaso se convierta en un peligro para la supervivencia del grupo, que ve cómo se airean sus contradicciones y fisuras: desmoraliza y desmoviliza al creyente o, aún peor, hace que flaquee su fe. Si se permite que la traición quede impune, quizá su ejemplo aliente la contestación interna, abriendo una puerta a futuras deserciones de consecuencias potencialmente desastrosas.

2 LEVINGER, Matthew y LYTLE, Paula Franklin: "Myth and mobilisation: the triadic structure of nationalist rhetoric", Nations and Nationalism, 7 (2001), pp. 175-194.

${ }^{3}$ CASQUETE, Jesús: En el nombre de Euskal Herria. La religión política del nacionalismo vasco radical, Madrid, Tecnos, 2009, p. 58.

4 VOLTAIRE: Tratado sobre la tolerancia, Barcelona, Público, 2010 [1 $1^{\text {a }}$ ed. 1767], p. 118. 
Todo movimiento procura conjurar los riesgos que trae aparejado el infiel aplicando una combinación de refuerzos positivos que incentiven la lealtad y negativos que desalienten la fuga de militantes. Cuanto más minoritaria y extremista sea una organización, más usual es que esté dispuesta a tomar medidas drásticas contra el renegado: la estigmatización, la restricción de oportunidades, la exclusión social o la violencia en diferentes grados. Llegado el caso, en una "guerra imaginaria" ${ }^{5}$ el abandono de la causa se puede acabar pagando con la vida, al igual que en la guerra real muchos ejércitos ejecutan a espías, traidores y desertores. Estos métodos sirven como castigo, pero también son un acto de pedagogía política con el objetivo de amedrentar al resto del grupo y, especialmente, a aquellos de sus integrantes que de una $u$ otra manera se cuestionan los dogmas de fe. Por tanto, los tránsfugas, aunque supongan una amenaza para el movimiento, también le son útiles.

ETA, Euskadi ta Askatasuna (País Vasco y Libertad), y su entorno civil, la autodenominada "izquierda abertzale" (patriota), se han sustentado en una narrativa bélica que encaja en la estructura ya descrita: desde su punto de vista, vascos y españoles llevan siglos enzarzados en un conflicto armado. Por ello, para comprender la cultura del ultranacionalismo es esencial analizar su imaginario. La mayoría de los personajes que pueblan el relato abertzale (el héroe, el mártir, el enemigo, etc.) ha sido estudiada en obras como En el nombre de Euskal Herria (2009), Sangre, votos, manifestaciones (2012) o el Diccionario ilustrado de símbolos del nacionalismo vasco (2012). No obstante, se ha pasado por alto una categoría que, a mi modo de ver, también resulta clave: la del traidor.

En el presente artículo se pretende colmar esta laguna historiográfica examinando cuál fue la reacción de ETA y su brazo político ante las disidencias que han juzgado como un beso de Judas desde 1958 hasta los años noventa del siglo XX. En primer lugar, las escisiones obreristas de ETA (ETA berri [nueva] y ETA VI) en la dictadura franquista. En segundo término, la heterodoxia de EE, Euskadiko Ezkerra (Izquierda de Euskadi), durante la Transición y la disolución a principios de los ochenta de un sector de ETApm, ETA político-militar. Tercero y último, los activistas de ETAm, ETA militar, que han colaborado con la policía o han optado por la reinserción. Se trata de dos diferentes tipologías del traidor (colectivo o individual), cada cual con su propia casuística, mas considero que existen coincidencias suficientes como para establecer un hilo conductor entre unos y otros.

\section{Estatutistas. EI PNV}

Durante la II República, el grupúsculo aranista Jagi-Jagi (Arriba-Arriba), antecedente remoto de ETA, tachó de renegados a los vascos no nacionalistas y a los "capitalistas" que habían "provocado" la inmigración maketa a Euskadi con la industrialización. Trifón Echebarría, uno de sus líderes, advertía que quien desistiera de la "lucha de razas" contra los españoles, "por muy grandes que sean las razones, es un traidor

\footnotetext{
5 La expresión en ELORZA, Antonio: La religión politica. "El nacionalismo sabiniano" y otros ensayos sobre nacionalismo e integrismo, San Sebastián, R\&B, 1995, p. 52.
} 
a la patria". A tales desertores se les declaraba una "franca guerra". Esa animadversión se extendió a las cúpulas de ANV, Acción Nacionalista Vasca, y el PNV cuando rehusaron formar parte de un frente independentista en $1936^{6}$. La Guerra Civil y el Estatuto de 1936 propiciaron que sucediera lo que los jagi-jagis tanto temían: la asociación de los nacionalistas moderados con un sector de los "españoles" (el PSOE, el PCE y las fuerzas republicanas).

Dicha relación, que continuó a lo largo de toda la dictadura franquista, fue criticada por la corriente más exaltada y fundamentalista del abertzalismo en el exilio americano, compuesta por jagi-jagis y aranistas ortodoxos del PNV. Como culpables se señalaba al dirigente jeltzale (militante del PNV) Manuel de Irujo y los altos cargos del Gobierno vasco, como los sucesivos lehendakaris (presidentes) José Antonio Aguirre y Jesús María Leizaola. Debido a su "estatutismo", fueron acusados de ser "degenerados", "vendepatrias" y "traidores". En síntesis, se podía leer, "el cáncer del nacionalismo vasco. Es vital destruirlo sin consideraciones". Y es que el independentismo a ultranza no admitía términos medios: "o patriotas o traidores"

Se trataba de un binomio muy similar al que se planteaba la nueva generación de nacionalistas radicales que se integró en ETA, organización fundada en 1958. Como se sentenciaba en su boletín Zutik (En pie) en 1963, "el que no colabora en la Resistencia es un traidor, y como tal será tratado (...). Que todos los vascos sepan que ha llegado ya el momento de la clasificación en héroes y traidores". En otro número se remarcaba que había que elegir "por o en contra. Ya se acabaron los certificados de patriotismo. Patriota es aquél que está luchando en la Resistencia o colaborando con ella (...). Todos los demás están del lado del opresor". En esa tesitura se encontraban aquellos jeltzales que no ayudaban a los presos etarras. "Traidores... cobardes... esclavos... Serán responsables en su día de su conducta". En Vasconia (1963), una obra que tuvo un enorme influjo ideológico en ETA, Federico Krutwig subrayó que "la traición más negra, más abominable, es aquella que justamente se opone a la libertad de la patria. Doblemente es traición, cuando procede de quienes se dicen nacionalistas" pero trabajaban "con partidos españolistas y republicanos". El lehendakari Leizaola, por ejemplo, no era más que "un colaborador gratuito de los enemigos del Pueblo vasco" porque no había enseñado euskera a sus hijos. "Un falso nacionalista que cometiese tal pecado de lesa patria hubiese merecido ser fusilado de rodillas y por la espalda, mientras que nosotros aún lo teníamos por presidente". Según había afirmado otro etarra en 1962, lo que animaba a los jóvenes vascos a tomar las armas era no ser "traidores a su condición de hombres y de ciudadanos de una Patria oprimida".

Pese a que la desconfianza era mutua, los ataques verbales no pasaron a mayores. El clima de hostilidad y competición entre la facción moderada y la radical podía enturbiar su relación, pero no romperla, porque, como reflexiona Gurutz Jáuregui, "el sentimiento y la ideología nacionalistas han actuado siempre como un auténtico cor-

\footnotetext{
6 Jagi-Jagi, 1-IV-1933, 9 y 16-V, 6 y 20-VI-1936.

7 Euzkadi Azkatuta, 1958?, n 66, IV-1963, y nº 87, I-1965, Frente Nacional Vasco, n 5, I-1965, y Sabindarra, $\mathrm{n}^{\circ}$ 18, 1971. No obstante, en 1945 los jagi-jagis, junto al resto de fuerzas antifranquistas de Euskadi, habían firmado el Pacto de Bayona en defensa del Gobierno vasco.

8 Zutik, XII-1961/I-1962, nº 8, XII-1962, nº especial Aberri Eguna, 1963, y n ${ }^{\circ} 12,1963$. KRUTWIG, Federico: Vasconia, Pamplona, Herritar Berri, 2006, pp. 18 y 360.
} 
dón umbilical imposible de cortar, incluso en los momentos difíciles"9. Las rencillas internas no hacían sino resaltar el aire de familia (abertzale). A ojos de los etarras el PNV era un partido anticuado, pasivo e inoperante. Empero, a pesar de algunos artículos puntuales de reproche, no se dudaba seriamente de la lealtad a la patria de los veteranos gudaris (soldados nacionalistas) del PNV que habían combatido en la Guerra Civil. Hacerlo, en cierto modo, hubiera supuesto condenar a sus propios padres.

\section{Obreristas y españolistas. ETA berri y ETA VI}

A raíz de su IV Asamblea (1965) ETA aspiró a combinar su tradicional ultranacionalismo con el socialismo. Esta novedosa influencia doctrinal propició que cristalizara en su seno una tendencia obrerista a cuya cabeza se situaron Patxi Iturrioz y Eugenio del Río. Tal y como le había pasado en 1902 a Tomás Meabe, uno de los discípulos predilectos de Sabino Arana, al profundizar en el estudio del marxismo dicha corriente fue perdiendo su fe en la causa abertzale. Un fortuito vacío de poder permitió a Iturrioz ponerse al frente de la Oficina Política, la encargada de editar el Zutik. Desde tal posición intentó forzar un giro a la izquierda de ETA, remplazando el "nacionalismo burgués" por un "patriotismo obrero", esto es, la narrativa bélica y xenófoba del abertzalismo radical por la dialéctica de la lucha de clases ${ }^{10}$.

El paulatino cambio de orientación de las publicaciones etarras encolerizó a José Luis Álvarez Enparantza (Txillardegi), uno de los fundadores y teóricos de la banda, quien desde finales de 1965 denunciaba a los miembros de la Oficina Política por "españolistas", "comunistas", "ateos en religión y apátridas en lo nacional", "norteñistas", "antivascos" e infiltrados del FLP, Frente de Liberación Popular. En definitiva, la suya era "una traición al pueblo vasco y a ETA". En abril de 1966 Txillardegi fundó la revista Branka (Proa) junto con Federico Krutwig con el objeto de combatir el influjo "españolista" de Zutik. El sector más nacionalista de la organización se unió a los ataques contra Iturrioz y sus partidarios ${ }^{11}$. Por idénticos motivos, Xabier Zumalde (el Cabra), el responsable del frente militar, se declaró en rebeldía en 1966. Su partida se separó de ETA para impulsar una fugaz guerrilla rural abertzale ${ }^{12}$.

Tal y como había exigido Txillardegi, en la primera parte de la V Asamblea (diciembre de 1966) se expulsó a la facción obrerista, calificada como "una desviación españolista" ${ }^{13}$. Poco después Iturrioz y Del Río fueron "condenados" a muerte por la nueva cúpula de ETA. Eduardo Uriarte (Teo) cuenta en sus memorias que a uno de los activistas "le mandaron hacer una fosa en una cuadra y, sospechando lo peor, se negó a continuarla". La sentencia nunca llegó a "ejecutarse". Probablemente la militancia

9 JÁUREGUI, Gurutz: Entre la tragedia y la esperanza. Vasconia ante el nuevo milenio, Barcelona, Ariel, 1997, p. 75.

10 FERNÁNDEZ SOLDEVILLA, Gaizka y LÓPEZ ROMO, Raúl: Sangre, votos, manifestaciones. ETA y el nacionalismo vasco radical (1958-2011), Madrid, Tecnos, 2012, pp. 298-299.

11 Informes y cartas de Txillardegi en HORDAGO, Equipo: Documentos $Y$, San Sebastián, Hordago, 1979, vol. IV, pp. 423-431, 449-453, 460-469, 486 y 507-509.

12 FERNÁNDEZ SOLDEVILLA, Gaizka: Héroes, heterodoxos y traidores. Historia de Euskadiko Ezkerra (1974-1994), Madrid, Tecnos, 2013, pp. 59-60.

13 HORDAGO: Documentos Y, vol. V, pp. 168-176. 
etarra todavía no estaba mentalizada para dar ese paso (su primer asesinato data de 1968), pero también hay que achacarlo, a decir de uno de los propios obreristas, Josetxo Fagoaga, a la "falta de recursos". Al fin y al cabo, como rememoraba José Luis Unzueta (Patxo), por aquel entonces la organización estaba "armada más del deseo de armarse que de armas reales" 14 .

Ahora bien, sí que había medios y voluntad para otro tipo de represalias, más si cabe cuando en enero de 1967 Iturrioz y Del Río crearon ETA berri, un partido marxista-leninista y no nacionalista, germen del MC, Movimiento Comunista. Contra sus integrantes se orquestó una campaña propagandística en la que no solo participó la ETA abertzale, apodada zarra (vieja), sino también ciertos sectores del PNV y otros grupúsculos como ELA berri, que, en opinión de Idoia Estornes, percibían en el obrerismo "una amenaza sobre el nuevo nacionalismo en su conjunto". El hostigamiento tomó diversas formas. Por una parte, hubo polémicas en la prensa y difamación pura y dura. Incluso se adujo que ETA berri era una creación de la dictadura franquista. Por otra parte, según Fagoaga, también surgió "la que sería seguramente la primera violencia de persecución": las actividades patrocinadas por los escindidos sufrieron "muy a menudo el boicot radicalmente activo de las gentes abertzales más combativas que actuaban en ellas como verdaderos reventadores profesionales armando unas trifulcas muy considerables". El grito de guerra de los saboteadores era "Españolistak kanpora!" (¡fuera los españolistas!). Por añadidura, como recuerda Javier Villanueva, los miembros de ETA berri fueron marginados socialmente. Les hicieron sentir como "apestados, lo más odiado, lo peor". Por ejemplo, cuando los obreristas entraban en un bar, todos los parroquianos nacionalistas salían de él. Este fue el origen del posterior acoso abertzale tanto a profesores vinculados al MC en determinadas ikastolas como al grupo musical Oskorri, cuyo cantante estaba afiliado a dicho partido. Todavía en septiembre de 1977 en una manifestación en San Sebastián los nacionalistas radicales acusaban a los militantes del Movimiento Comunista de ser unos "traidores" y los mandaban "a Madrid"15.

Irónicamente, bastantes de los que habían ejercido de perseguidores de ETA berri acabaron experimentando una evolución semejante $y$, en consecuencia, pasaron a ser perseguidos ellos mismos. En 1970, tras la caída de la dirección de la banda el año anterior, ETA se encontraba dividida por una cuestión crucial: ¿debía primar el nacionalismo o el socialismo? El Comité Ejecutivo provisional de Patxo Unzueta pretendía transformar la organización en un partido leninista, a lo que se negaban tanto la tendencia "anticolonialista" de Krutwig como el frente militar de Juan José Etxabe, partidario de la pureza abertzale y la apuesta estratégica por el terrorismo ${ }^{16}$.

14 URIARTE, Eduardo: Mirando atrás. Del proceso de Burgos a la amenaza permanente, Barcelona, Ediciones B, 2005, p. 67. Hika, 147 (IV-2003). UNZUETA, José Luis: "La V Asamblea de ETA", Saioak 4 (1980), p. 3.

15 ESTORNES ZUBIZARRETA, Idoia: “Abandonando la casa del padre. Eusko Langileen AlkartasunaSolidaridad de Trabajadores Vascos (Movimiento Socialista de Euskadi), 1964-1969”, Historia Contemporánea, 40 (2010), pp. 152-157. La cita de Fagoaga en Hika, 147 (IV-2003). Entrevista a Javier Villanueva, Guernica, 9-III-2007. Zer egin?, no 19, 1-X-1977.

16 FERNÁNDEZ SOLDEVILLA, Gaizka y LÓPEZ ROMO, Raúl: Sangre, votos ..., p. 299. 
Los nuevos obreristas consiguieron que sus tesis fueran aprobadas en la VI Asamblea (agosto de 1970), aunque tal resultado trajo aparejado la división del grupo. El grueso de la militancia, que abandonó las armas y el nacionalismo, fue conocido a partir de entonces como ETA VI. Los sectores abertzales, que no reconocieron la legalidad de aquella asamblea, denunciaron el "liquidacionismo españolista" de la "fracción marxista-leninista española" y formaron ETA $\mathrm{V}^{17}$.

En la consiguiente disputa por las históricas siglas de la organización, a pesar de que ETA VI tenía a su favor la "legalidad" y el mayor número de activistas, prevaleció ETA V. La derrota de los obreristas se debió, en parte, a sus incoherencias ideológicas, sus desavenencias internas y su mala fortuna (el abortado rescate a los condenados en el proceso de Burgos -1970- o la detención de su cúpula en marzo de 1971). No obstante, entraron en juego otros vectores. En primer lugar, ETA V logró una gran baza publicitaria con el secuestro del cónsul de la República Federal Alemana en San Sebastián. En segundo término, los presos más prestigiosos de la banda, como Mario Onaindia, que inicialmente se habían posicionado a favor de ETA VI, terminaron tomando partido por los ultranacionalistas ${ }^{18}$. Tercero, ETA V se embarcó, en palabras de José María Garmendia, en un "ataque constante a ETA-VI, utilizando la acusación de españolismo con una ferocidad implacable, aun a riesgo, en ocasiones, de caer en el racismo". En un Zutik de 1971 se leía que la de aquellos "quistes hispanos" era una "traición radical a la causa vasca". Y es que "a VI Asamblea le duele España, como a aquellos otros traidores que fueron Unamuno y Maeztu". Un texto de Etxabe imputaba a los "so españolazos" el crimen de haber donado un millón de pesetas a "los españoles de Granada" (unos obreros en huelga). Una vez más, la banda pudo contar con el vital apoyo de buena parte del resto de la comunidad abertzale: el grupo Branka de Txillardergi, la asociación Anai Artea (Entre Hermanos) de Telesforo Monzón, ELA-MSE y las juventudes del PNV (EGI), que ejercieron un papel fundamental. Sin su auxilio ETA V, que carecía de infraestructura y presencia organizada en el interior de España, difícilmente hubiera prevalecido. La campaña propagandística llegó hasta el exilio venezolano, desde el cual los aranistas más ortodoxos achacaron a ETA VI haber sido seducida por los odiados inmigrantes "españoles". Pero, ¿por qué tan generalizado respaldo? Siguiendo a Garmendia, "toda la derecha vasca se vuelca en la operación, en un movimiento del conjunto del nacionalismo por recuperar como sea la base social etarra, peligrosamente orientada por los llamados españolistas". Valga como ilustración una carta que en julio de 1971 Txillardegi escribió a Manuel Irujo advirtiéndole de "un fenómeno nuevo y horroroso": "el paso de una idea abertzale a un marxismo-leninismo español se está produciendo con regularidad impresionante en los medios y las organizaciones euskaldunes incluso (...). Creo así que Euzkadi se nos ha escapado de las manos a todos". A su parecer, solo había "un comienzo de solución: que los abertzales (...) vayamos decididos a recuperar la iniciativa y la juventud" 19 .

17 HORDAGO: Documentos $Y$, vol. IX, pp. 451-452.

18 La carta de los presos de Cáceres en Hautsi, no 3, IV-1973.

19 GARMENDIA, José María: Historia de ETA, San Sebastián, Haranburu, pp. 443 y 510. Zutik n 60, 1971. La carta de Etxabe en HORDAGO: Documentos Y, vol. vol. IX, pp. 455-456. Sabindarra, n 22, XI/ XII-1971. La carta de Txillardegi en http://www.euskomedia.org/PDFFondo/irujo/1824.pdf 


\section{Vendepatrias y arrepentidos. ETApm, EIA y EE}

En 1974 las disputas estratégicas, que no ideológicas, hicieron que ETA V se fragmentase de nuevo. Una minoría de sus activistas, los que únicamente confiaban en la violencia, creó ETAm, ETA militar, el referente de varias formaciones que en 1978 dieron lugar a la coalición HB, Herri Batasuna (Unidad Popular). La mayoría de la organización pasó a denominarse ETApm. Cuando su intento de compaginar "lucha armada" y "lucha de masas" naufragó, Eduardo Moreno Bergaretxe (Pertur), el líder ideológico de los polimilis, propuso un novedoso giro para que la banda se adaptase a la Transición: constituir un partido de corte leninista que se presentase a las elecciones democráticas en alianza con la extrema izquierda y que actuara como "vanguardia dirigente" de todo el movimiento, pasando ETApm a un papel secundario en la retaguardia. El proyecto de Pertur, que subvertía algunos de los fundamentos de la narrativa de lo que luego se ha venido a llamar "conflicto vasco" (el protagonismo de ETA, el odio a los no abertzales, etc.) provocó la irritación del sector más nacionalista y militarista del grupo, los berezis (especiales), quienes le acusaban de ser un hereje que estaba planteando la "liquidación" de la "lucha armada".

A finales de abril de 1976, aduciendo que había incumplido ciertas medidas de seguridad, los intransigentes secuestraron a Moreno Bergaretxe, pidiendo, además, la competencia de juzgarlo y aplicar la sentencia. El resto de los polimilis exigió su puesta en libertad. La tensión creció hasta extremos casi insoportables, como prueba una carta que Pertur escribió a su familia: "estos bestias han creado un clima tal en la organización, que han transformado ETA en Euskadi norte no en un colectivo de revolucionarios, sino en un estado policial donde cada uno sospecha del vecino y este del otro". El 23 julio de 1976 el ideólogo de ETApm desapareció sin dejar rastro. Las últimas personas con las que se le vio, Miguel Ángel Apalategi (Apala) y Francisco Mujika Garmendia (Pakito), eran precisamente dos de los cabecillas de los berezis. No es de extrañar que se les considere sospechosos de su asesinato, aunque lo cierto es que no hay pruebas concluyentes al respecto. Sea como fuere, en septiembre de 1977 el grueso de los "especiales" acabó integrándose en ETAm ${ }^{20}$.

Pese a la muerte de Moreno Bergaretxe, ETApm siguió fielmente sus planes: fundó EIA, Euskal Iraultzarako Alderdia (Partido para la Revolución Vasca), que se presentó a los comicios bajo la cobertura de Euskadiko Ezkerra, una coalición con el Movimiento Comunista heredero de ETA berri. El 15 de junio de 1977 esta candidatura transversal entre el nacionalismo radical y la extrema izquierda obtuvo dos parlamentarios. Por el contrario, ETAm y su entorno llamaron a la abstención para no legitimar la Transición democrática, que consideraban una mera continuación de la dictadura franquista. Aquella divergencia condujo al decisivo cisma de la "izquierda abertzale" en dos facciones irreconciliables: la intransigente de los milis y HB y la flexible de los polimilis y EIA, formación que en octubre de 1977 eligió como secretario general a Mario Onaindia. Se trataba de la figura más carismática de entre los condenados en el proceso de Burgos, pero, debido a su progresivo posibilismo

20 FERNÁNDEZ SOLDEVILLA, Gaizka: Héroes, heterodoxos..., pp. 68-97. La carta en Punto y Hora de Euskal Herria, 26-I a 1-II-1978 
no tardó en caer en desgracia a ojos de los nacionalistas más sectarios. Él mismo recordaba que en 1977 un antiguo conocido no solo le había negado la condición de vasco, sino que incluso le advirtió que "si yo fuera militante de ETA os pegaba un tiro". A la postre, como indica Jesús Casquete, "los héroes, o están muertos, o lo son en precario, esto es, sin garantía alguna de alcanzar la eternidad. El estatus del héroe vivo puede ensombrecerse de la noche a la mañana". Los ataques de ETAm y su brazo electoral se centraron en Onaindia para despojarle de su condición de emblema nacional. Como se podía leer en Tierra Vasca, "nos has traicionado, Mario, nos has dejado en la cuneta". No tuvo más remedio que asumirlo. En 1981 declaraba: "ya sé que nos llaman traidores, porque cuanto hagamos los demás será para ellos una traición siempre". Durante la última etapa de su vida tuvo que llevar escolta policial por estar amenazado de muerte por ETA, al igual que sus compañeros del Partido Socialista. La inquina de la "izquierda abertzale" le persiguió más allá de su muerte el 31 de agosto de 2003. Antton Jauregizuria, un histórico ultranacionalista, definió al recién fallecido Onaindia como "un tránsfuga, un arrepentido, o, más llanamente un renegado a sus amigos, compañeros y nación" 21 .

Desde la perspectiva de HB y los milis, aparte de acudir a la primera cita con las urnas de la democracia (para más inri, junto con los "españolistas" del MC), los euskadikos habían cometido otros crímenes de lesa patria. Por sintetizar, los afiliados a EIA experimentaron una compleja evolución que les llevó desde la complicidad con el terrorismo al compromiso cívico con la paz, desde la visión instrumental de la instituciones (como una plataforma para destruir la "democracia burguesa" desde dentro) a la asunción del marco constitucional, desde el comunismo revolucionario a la socialdemocracia y desde el independentismo al autonomismo. Tal vez el hito de esta transición dentro de la Transición fuera su respaldo al Estatuto de Guernica de 1979, que fue considerado no solo la solución para el encaje de Euskadi en España, sino también la mejor manera de asegurar la convivencia de la muy plural sociedad vasca. A decir del parlamentario de EE Juan Mari Bandrés, se trataba de un "tratado de paz" que ponía punto y final al conflicto armado contra el "Estado". En contraste, desde el prisma de HB, el Estatuto evocaba "al triste y traidor "abrazo de Vergara" de 1839. Al contrario que sus antecesores, los ingenuos carlistas, los abertzales no se iban a dejar engañar: su "guerra" solo terminaría cuando el Gobierno cediese a sus pretensiones (la "Alternativa KAS") 22 .

ETAm y su entorno civil se negaban a reconocer la democracia parlamentaria, contra la que se enfrentaron violentamente. Cierta dosis de dicha agresividad se orientó contra EIA, que fue percibido como una especie de traición colectiva a la patria. A la altura de 1978, para los milis la formación de Onaindia era "sencillamente antiETA" y estaba dando un "espectáculo de claudicaciones en cadena". Era su "deber denunciar la política de EIA e intentar recuperar lo que se pueda de su militancia". Al

21 ONAINDIA, Mario: Carta abierta sobre los perjuicios que acarrean los prejuicios nacionalistas, Barcelona, Península, 1995, p. 45. CASQUETE, Jesús: En el nombre de ..., p. 59. Tierra Vasca, no 5, VI-VI-1981. Tiempo, 9 al 15-VI-1981. Gara, 3-IX-2003. Tampoco el PNV le perdonó nunca su supuesta traición a la patria. Iñaki Anasagasti escribía recientemente que Onaindia había pasado "de ser miembro de ETA a ser el converso constitucional más furibundo" (Karma, $\mathrm{n}^{\circ}$ 133, III-2011).

22 FERNÁNDEZ SOLDEVILLA, Gaizka: Héroes, heterodoxos..., pp. 98-189. Egin, 18 y 22-VII-1979. 
año siguiente un portavoz de la banda repudió oficialmente al partido: ya ni siquiera podía ser considerado parte de la "izquierda abertzale". Era una excomunión en toda regla ${ }^{23}$.

Los euskadikos sufrieron una sistemática campaña de desprestigio. En Egin eran tachados de "colaboradores del neofranquismo" mientras que Onaindia era juzgado como un nuevo Petain. Para el líder de HB Patxi Zabaleta los miembros de EE eran los "correveidiles, monaguillos, recadistas y puntas de lanza de lo que es el PNV". Un lector de dicho periódico avisaba: "Ya os pasaremos la factura de la traición". Según deja constancia en sus memorias el dirigente ultranacionalista Jon Idígoras, "éramos la voz de su conciencia traidora y claudicante". Cuando en 1979 EIA se dispuso a conmemorar el fusilamiento en 1975 de los dos mártires por antonomasia de ETApm, Juan Paredes (Txiki) y Ángel Otaegi, el hermano del primero escribió: “Cómo tenéis el valor de usar una fecha tan importante para el pueblo para conseguir lo contrario por lo que lucharon Txiki y Otaegi? Yo estoy convencido de que si mi hermano o cualquiera de nuestros muertos viviera, no lo permitirían". El dominio de la prensa abertzale permitió a HB amordazar a los antiguos correligionarios de aquellos dos polimilis, muchos de los cuales militaban en EIA o ETApm. A las palabras les acompañaron los hechos. El mitin que la formación de Onaindia había organizado en Zarauz para recordar a Txiki y Otaegi fue furiosamente saboteado por los intransigentes. Se trataba de una forma muy efectiva de desposeer a EIA de la herencia simbólica que había recibido de los polimilis, una importantísima baza política que, utilizando la terminología de Jesús Casquete, HB vampirizó ${ }^{24}$.

Los simpatizantes de ETAm fueron arrojando del espacio público a los euskadikos, acosados en las fiestas populares y cualquier tipo de concentraciones que convocaran. Verbigracia, sus manifestaciones a favor del Estatuto de autonomía fueron atacadas por contramanifestantes radicales al grito de "españolistas", "vendepatrias" y "traidores". No faltaron las amenazas ni la violencia. Tampoco en la cárcel ni al otro lado de la frontera, en el País Vasco francés, donde en ocasiones los milis agredían a los menos numerosos activistas de ETApm ${ }^{25}$.

Esta presión, a la que hay que sumar los errores del propio equipo de Onaindia, cuya atención estaba cada vez más volcada en las instituciones democráticas, permitió a HB disputar y luego arrebatar a EIA la mayor parte del legado de ETA y el nacionalismo radical: el diario Egin, el sindicato LAB, las Gestoras pro amnistía, el control de la calle, las figuras de los mártires etarras, etc. Tal derrota es una de las claves que permite explicar por qué en los sucesivos comicios de 1979 y $1980 \mathrm{HB}$, una coalición sin experiencia ni tradición, sobrepasó con facilidad a EE, que se tuvo que conformar con un tercio del caladero electoral de la "izquierda abertzale".

La manifiesta hostilidad de HB probablemente restó votos a EIA, pero, desde luego, no amedrentó a su militancia ni a sus dirigentes. Por el contrario, el rechazo y la presión supusieron un refuerzo para la renovación doctrinal que encabezaba Onaindia. Los euskadikos mantenían que tanto abertzales exaltados como jeltzales, que

\footnotetext{
23 Zutabe, no 1, y Punto y Hora de Euskal Herria, 25-X-1979

24 Egin, 14-II, 19-VII, 23 al 30-IX, 12-X, y 20-XII-1979. IDÍGORAS, Jon: El hijo..., p. 330.

25 Hitz, no $^{\circ}$, VII-1979 y n ${ }^{\circ}$ 7, VI-1980, Egin, 22 y 27-VII y 23-IX-1979, Deia, 28-IX-1979, ABC, 30-IX1979, El País, 24-VII y 2 y 21-X-1979, Diario 16, 22-X-1979, y Ere, nº 7, 25-X al 1-XI-1979.
} 
también les criticaron por su tibieza, formaban parte de "un nacionalismo etnicista, exclusivista que considera 'pueblo honesto' a todo aquel que comulgue con sus ideas y 'traidor vendepatrias' a quien se le ocurra divergir y no opinar de la misma forma". En consecuencia, tal y como rememora José María Salbidegoitia, "cuanto más sales, más heterodoxo eres, más te rechaza y te critica la tribu. Al final eres tú el que rechazas la ortodoxia del grupo y su control inquisitorial. Pero para eso hace falta tener madurez ideológica y carácter. Porque inmediatamente te sientes 'extranjero en tu propio país"'26.

El talón de Aquiles de EIA era su interdependencia respecto a ETApm, una organización terrorista que fue responsable de 22 asesinatos. Cuando la lógica parlamentaria y la del terrorismo resultaron manifiestamente incompatibles, Onaindia, sin consultar a sus compañeros, empezó a reunirse con Juan José Rosón, el ministro del Interior. En febrero de 1981 estos encuentros fueron legitimados por una asamblea extraordinaria de EIA y la declaración de tregua de los polimilis. Así, dieron pie a unas negociaciones propiamente dichas, gracias a las cuales se acordó una amnistía encubierta ("paz" por presos), que permitió que una facción de ETApm, los séptimos, abandonase las armas. La reinserción social sirvió para que cientos de exterroristas volviesen a la vida civil. Es uno de los factores que propició que los niveles de violencia se redujeran en 1981 y los años sucesivos. Se trató de una de las mayores contribuciones que EIA-EE y los gabinetes de UCD, Unión de Centro Democrático, hicieron a la convivencia democrática en el País Vasco ${ }^{27}$.

La generosa oferta que el Gobierno había lanzado a los polimilis también incluía explícitamente a los milis. Mas la cúpula de ETAm no solo despreció el "liquidacionismo", sino que se puso en guardia, alarmada ante la eventualidad de que su militancia, al comprobar el alcance del proceso, se viera seducida por lo que se pintaba como una cobarde desbandada. Años después Iñaki Egaña Sevilla, uno de los propagandistas orgánicos de la "izquierda abertzale", apostilló que la reinserción había sido "un instrumento político ante todo, encaminado a atacar las condiciones sociales de las que se sustenta ETA, su credibilidad y legitimidad social". No lo fue, pero sí fue vista como tal. En consecuencia, para evitar que sus activistas cayeran en la tentación, la banda y su entorno civil se propusieron deslegitimar y entorpecer la vuelta a casa de los séptimos. No se trataba tanto de escarmentar a los integrantes de ETApm VII Asamblea como de intimidar a los de ETAm, a quienes se colocaba ante una delicada disyuntiva: fidelidad o correctivo. ¿Cómo se transmitió tan ejemplarizante lección? En primer lugar, los líderes de HB sirvieron de altavoz a los designios de los terroristas. Por ejemplo, Jon Idigoras acusó a EE de ser "un elemento peligroso y disolvente en Euskadi", mientras que para Txomin Ziluaga el partido de Onaindia había tomado el "camino" de la "deserción". El vocablo era inequívoco. Segundo, la prensa afín a la facción intransigente de la "izquierda abertzale" repitió machaconamente la etiqueta de "arrepentidos", intentando relacionar a los expolimilis con los collaboratori di giustizia (colaboradores de la justicia, conocidos como pentiti, "los que se arrepienten") de las Brigadas Rojas italianas. Era una equiparación arbitraria e interesada, ya

\footnotetext{
26 Hitz, no 1, VII-1979. Entrevista a José Maria Salbidegoitia, Vitoria, 5-II-2008

27 FERNÁNDEZ SOLDEVILLA, Gaizka: Héroes, heterodoxos..., pp. 226-263.
} 
que los séptimos no renegaron de su pasado ni cooperaron con la policía. Tercero, el diario Egin publicó la lista negra de los presos que se habían acogido a las medidas de gracia. La difusión de sus nombres y apellidos fue percibida como una coacción. Algunos de los que habían firmado, atemorizados, dieron marcha atrás y se descolgaron del proceso. En cuarto lugar, los abertzales más exaltados procuraron amilanar a los reinsertados que volvían a sus localidades de origen: hubo agresiones, siembra de pasquines, pintadas, quema de coches, etc. Todo con el fin de marcarlos públicamente como traidores. Quinto y último, el sector de ETApm que había decidido continuar con el terrorismo, los octavos, emprendió su propia operación de descrédito. Como muestra un botón. En uno de sus panfletos se contraponía una fotografía de la rueda de prensa en la que los séptimos habían anunciado el abandono de las armas con imágenes de la Guerra Civil: por una parte, un grupo de gudaris (soldados nacionalistas vascos) recién rendidos a las tropas franquistas; por otra, el ingeniero Alejandro Goicochea, que se había pasado al bando insurrecto con los planos del "Cinturón de hierro", las fortificaciones defensivas del Bilbao republicano. La organización, además, amenazó de muerte a los reinsertados, a sus abogados y a los líderes de $\mathrm{EE}^{28}$.

El regreso a Euskadi de los exactivistas de ETApm VII Asamblea tuvo su eco en otros grupos terroristas. Por un lado, un significativo número de los octavos (los mismos que habían tachado a sus excompañeros séptimos de "traidores" y "arrepentidos") se acogió a las medidas de gracia auspiciadas por el entonces senador del PNV Joseba Azkarraga. Por otro lado, también se reinsertaron por diferentes vías bastantes de los miembros de los Comandos Autónomos Anticapitalistas. Al cabo, la experiencia de ETApm VII sirvió de modelo para la disolución de otras bandas, como fue el caso de Terra Lliure (Tierra Libre) en Cataluña a mediados de la década de los $90^{29}$.

No obstante, la experiencia apenas afectó a ETAm. Sus medidas de seguridad resultaron efectivas: muy escasos milis tuvieron el valor de sumarse a la reinserción y lo hicieron de manera tan cauta y discreta que su defección no salió a la luz. Por consiguiente, no despertaron el temible interés de la organización, aunque, como se verá más adelante, no todos los exetarras tuvieron tanta suerte. Fuera como fuese, la disolución de ETApm no solo no debilitó a ETAm, sino que le confirió una baza simbólica de primer orden: la instrumentalización de la figura del renegado, que sirvió para ilustrar los riesgos de la pérdida de la fe y la transgresión de los dogmas sagrados: la caída en desgracia, el rechazo social y la expulsión de la comunidad de los elegidos. Modelo negativo que evitar, el séptimo, y por extensión el euskadiko, fue objeto del odio colectivo de los ultranacionalistas, cohesionando sus vínculos internos y permitiéndoles así ratificar su compromiso con la causa patriótica y la estrategia terrorista, esto es, con ETAm. Todavía a finales de los ochenta uno de los líderes de la banda,

28 EGAÑA SEVILLA, Iñaki: Diccionario histórico-político de Euskal Herria, Tafalla, Txalaparta, 1996, pp. 72-74. Zuzen, no 12, IX-1981, Deia, 4-VIII-1982 y El País, 14-I, y 28-X-1983, y 12-VIII-1986, Hemendik, 27-I-1983, Deia, 10-VIII-1982, y 14-I, 15-V, 29-X-1983, Diario 16, 14-I, y 16-V-1983, y 29-X-1983, Egin 1-III-1981, 3 y 10-VIII y 2-X-1982 y 23-II-1983, y Punto y Hora de Euskal Herria, 29-X al 5-XI-1982, 26-XI al 3-XII-1982, y 6 al 13-XI-1986. "Después de 40 años esto”, XI-1982, Lazkaoko Beneditarren Fundazioa, caja ETA 6, 1.

29 ESCRIVÁ, María Ángeles: El camino de vuelta. La larga marcha de los reinsertados en ETA, Madrid, El País Aguilar, 1998, pp. 105-142. ZIRIKATU: Komando Autonomoak: sasiaren arantzakada. Una historia anticapitalista, Bilbao, Felix Likiniano, 1999, pp.111-118. 
Eugenio Etxebeste (Antxon), señalaba que "el Gobierno quiere hacer con nosotros lo mismo que con los 'liquis' [los reinsertados]. Pretende que ETA destruya todo el Movimiento Vasco de Liberación Nacional. Pero nosotros no somos los "liquis"" 30 .

Algo muy similar se podría decir de la imagen que de EE proyectó la "izquierda abertzale" a lo largo de la década de los ochenta. A decir de Patxo Unzueta, "el disidente (simbolizado por figuras como Onaindía y, en general, por lo que representa Euskadiko Ezkerra) es considerado con frecuencia el enemigo principal". Como poco, provocaba el mismo nivel de animadversión que quienes el ultranacionalismo tradicionalmente imaginaba como sus adversarios: España, todo lo que sonara a "español" (desde la misma palabra a la lengua en sí) y los vascos no abertzales. Así, un texto firmado por el autodenominado Movimiento Vasco de Liberación Nacional clasificaba a EE como "protagonista de la reforma franquista". Pese a que compartía tan dudoso privilegio con el PNV, la acción de los euskadikos había sido "más dañina para la causa de la liberación nacional vasca", ya que, gracias a ellos (y especialmente "a personajes como M. Onaindia y J. M. Bandrés"), "el mensaje de la reforma del franquismo" había sido atendido por un porcentaje sustancial del pueblo vasco. Para ETAm y su entorno civil su "denuncia de EE es, por tanto, sin paliativos de ningún género, ya que el peor enemigo es el de casa, y mucho más cuando es traidor". No se iba a atentar "contra ellos", pero se sentenciaba que "el próximo futuro de nuestro pueblo los condenará implacablemente" 31 .

Se acusó a Mario Onaindia y Juan Mari Bandrés de ser "portavoces del llamamiento a la comprensión y colaboración en el tema policial". Y es que la "izquierda abertzale" siempre fue propensa a las teorías de la conspiración. Así se presentó a EE como una maquinaria al servicio del "imperialismo", financiada y potenciada por el "Estado español" para luchar contra ETA. Los euskadikos habían protagonizado un "cambalache de traiciones y arrepentimientos vergonzoso protagonizado por Bandrés y Onaindia con el patrocinio publicitario de los medios de comunicación-intoxicación pagados con el fondo de reptiles del Plan ZEN [Zona Especial Norte]'. HB llegó al extremo de atribuir a Bandrés la instigación de los GAL, Grupos Antiterroristas de Liberación. De esta manera, cuando en 1984 dicha banda asesinó a Santiago Brouard, teniente alcalde de Bilbao por la coalición ultranacionalista, se prohibió que euskadikos y socialistas (no así los jeltzales, que fueron admitidos sin problemas) mostraran sus respetos al difunto en la capilla del ayuntamiento. Su presencia se interpretaba literalmente como "un insulto". La violencia del entorno de HB no solo fue verbal. Al igual que había ocurrido durante la Transición, las manifestaciones convocadas por los euskadikos en protesta contra los atentados terroristas de ETA fueron atacadas por nacionalistas radicales al grito de "españolistas" y "fuera de Euskadi" 32.

30 RAMÍREZ, Pedro J.: La rosa y el capullo. Cara y cruz del felipismo, Barcelona, Planeta, 1989, p. 183.

31 UNZUETA, José Luis: Los nietos de la ira. Nacionalismo y violencia en el País Vasco, Madrid, El País Aguilar, 1988, p. 86. MOVIMIENTO VASCO DE LIBERACIÓN NACIONAL: "Euskadi en guerra. Un horizonte para la paz", en VVAA: Euskadi en guerra, Bayona, Ekin, 1987, p. 243.

32 Zutabe, $\mathrm{n}^{\circ} 32,1982, \mathrm{n}^{\circ} 40, \mathrm{I}-1985, \mathrm{n}^{\circ} 42, \mathrm{X}-1985, \mathrm{y}^{\circ} 46$, VII-1987, Zuzen, $\mathrm{n}^{\mathrm{o}} 12$, IX-1981, $\mathrm{n}^{\circ} 24$, IX-1982, no 30, III-1983, y no 40, II-1984, Eraiki, no 4, X-1982, Egin, 12-II-1980, 28-V-82, Zer egin?, $22-$ XI-1981, y Hemendik, XII-1984, El País, 29-XI-1982, 17 y 19-VII, y 28-IX-1985, y 12-VIII-1986, y Punto y Hora de Euskal Herria, 25-X-1979, 6 al 13-XI-1981, 29-I al 5-II-1982, y 2 al 9-IV-1982. 
En 1993 EE se fusionó con el Partido Socialista de Euskadi, la federación vasca del PSOE, dando lugar al PSE-EE. Para la "izquierda abertzale" se trató de la culminación final de una larga cadena de crímenes contra la patria. Con aquella convergencia se escenificaba un cambio de trinchera que, en realidad, había tenido lugar años atrás, cuando los euskadikos se negaron a acatar las órdenes de ETAm. Egin lo sintetizó con un elocuente titular: "los antiguos dirigentes de EE asumieron públicamente su españolidad". La editorial Txalaparta se apresuró a publicar un panfleto sobre la traición de los euskadikos. El fin de la herejía fortaleció la ortodoxia doctrinal del nacionalismo radical y violento, así como su servil devoción a ETAm. Tal y como sugiere Mikel Arriaga, el "estrepitoso descalabro de la aventura Euskadiko Ezkerra" actuó "de modo sobresaliente como referencia negativa reafirmadora" para "mantener encendida la llama de la esperanza comunitaria, del sueño generacional, utópico siempre, en los corazones de un, en un primer momento, heterogéneo sujeto revolucionario", el de $\mathrm{HB}^{33}$.

\section{Infiltrados y confidentes. ETAm I}

En la III Asamblea de ETA, celebrada en el País Vasco francés en 1964, se aprobó la ponencia "La insurrección en Euzkadi", redactada por Julen Madariaga. En aquel texto se subrayaba que el compromiso de un "combatiente de la Resistencia Vasca" únicamente podía acabar con "la victoria final, la cárcel, o la muerte". Se entendía que un etarra pudiera fallecer a manos de los ocupantes "españoles", pero tampoco se descartaba que fuera a las de sus propios camaradas. Es más, desde la perspectiva de Madariaga, era "menos escandaloso fusilar traidores que fusilar enemigos". Como señala Florencio Domínguez, a lo largo de su larga historia la banda "no ha tenido que hacerlo [ajusticiar a alguno de sus miembros] demasiadas veces, pero las ocasiones en que lo ha hecho constituyen una lección grabada a fuego en la memoria de cada militante y de cada simpatizante" ${ }^{34}$. Por más que la causa directa de estos asesinatos fuese la transgresión de determinadas creencias o normas grupales, por lo general estaban planteados más como actos de pedagogía que como meros castigos.

Como se recordará, escasamente tres años después de la III Asamblea, Patxi Iturrioz y Eugenio del Río, cabezas visibles de la corriente obrerista, fueron "condenados" a la pena capital por sus excompañeros, aunque nunca se llegó a atentar contra su vida. Mikel Lejarza (Lobo) recibió la misma sentencia en 1975. Se trataba de un agente del SECED (Servicio Central de Documentación) infiltrado en ETApm, gracias a cuya actuación la estructura operacional de la banda quedó prácticamente desarticulada en el verano de 1975. Decenas de polimilis fueron arrestados, incluyendo a su máximo dirigente, Iñaki Mujika Arregi (Ezkerra), y al de los berezis, Iñaki

33 Egin, 28-III-1993. EGIDO, José Antonio: Viaje a la nada. Principio y fin de Euskadiko Ezkerra, Tafalla, Txalaparta, 1993. ARRIAGA, Mikel: ...y nosotros que éramos de HB... Sociología de una heterodoxia abertzale, San Sebastián, Haranburu, 1997, p. 156

34 "La insurrección en Euzkadi", en HORDAGO: Documentos Y, vol. III, pp. 30 y 31 . Énfasis en el original. DOMÍNGUEZ IRIBARREN, Florencio: Dentro de ETA. La vida diaria de los terroristas, Madrid, Aguilar, 2002, p. 279. 
Pérez Beotegi (Wilson). Los polimilis inundaron Euskadi de pasquines con el rostro de Lejarza, pero no consiguieron dar con él para vengarse ${ }^{35}$.

Las devastadoras dentelladas de la operación Lobo y la ausencia de Ezkerra y Wilson condicionaron la suerte de ETApm y explican, hasta cierto punto, tanto la renovación estratégica propuesta por Pertur como la radicalización de los berezis. Precisamente estos secuestraron a Moreno Bergaretxe en abril de 1976 aduciendo que se había saltado las normas de seguridad al comunicarse directamente con su amigo Mujika Arregi, preso en la cárcel de Burgos. Ese mismo verano fue raptado por segunda vez, suceso que seguramente culminó con su asesinato. En caso de que los autores hubieran sido los berezis, se trataría de la primera "ejecución" de un "traidor" en el seno de ETA.

Cuatro años después de la misteriosa desaparición de Pertur otro etarra sufrió un destino (presumiblemente) similar: José Miguel Etxeberria Álvarez (Naparra o Bakunin), un destacado dirigente de los CAA, Comandos Autónomos Anticapistalistas, quien tenía a sus espaldas un largo historial de transfuguismo: afiliado a la trotskista LCR, Liga Comunista Revolucionaria, había pasado a ETApm, encuadrándose en los berezis, y luego, junto a estos, ingresó en ETAm. Los desencuentros entre la autoritaria cúpula de la organización y las ideas libertarias de Etxeberria le llevaron a abandonar las filas milis para unirse a los autónomos a finales de 1978. En 1980 Naparra, quien buscaba nuevas formas de abastecimiento para los CAA, contactó con un traficante internacional de armas, el cual ya mantenía una relación comercial con los milis. Con el objetivo de resolver aquel conflicto de intereses la dirección de ETAm se citó con Etxeberria Álvarez el 11 de junio de 1980. Uno de sus compañeros lo trasladó hasta el lugar del encuentro, San Juan de Luz. Nunca se volvió a ver a Naparra, por lo que se sospecha que fue eliminado por los milis. Los Comandos Autónomos manifestaron que se había repetido el caso Pertur ${ }^{36}$.

Hasta ahora ha sido imposible esclarecer qué les ocurrió realmente a Moreno Bergaretxe y Etxeberria Álvarez. La responsabilidad de los etarras (berezis o milis) parece, a priori, una suposición bastante razonable, pero está por demostrar. A falta de evidencias, no nos hayamos en condiciones de descartar la actuación de un comando parapolicial o algo por el estilo. De cualquier manera, ambos episodios afectaron notablemente a los activistas de ETApm y los CAA, haciéndoles recelar de ETAm (donde acabaron recalando los berezis, no lo olvidemos). Al fin y al cabo, los milis son los únicos que han empleado abiertamente las "ejecuciones" de "renegados" con fines ejemplarizantes.

Con todo, su tentativa inicial fue un fiasco. Gonzalo Santos Turrientes Urquiola (El Box) había formado parte de ETA a mediados de los años sesenta, época en la que, según sus excamaradas, actuó como confidente policial. Como demostraron las amenazas recibidas, el paso del tiempo no ayudó a borrar su supuesta delación. En

35 VINADER, Xavier: Operación Lobo. Memorias de un infiltrado en ETA, Madrid, Temas de hoy, 1999. La condena a muerte de Lejarza en Hautsi, $n^{\circ} 8$, XII-1975. Su historia ha inspirado un largometraje: Lobo (Miguel Courtois, 2004).

36 Ere, 16 al 23-VII-1980. ALONSO, Rogelio, DOMÍNGUEZ IRIBARREN, Florencio y GARCÍA, Marcos: Vidas rotas. Historia de los hombres, mujeres y niños víctimas de ETA, Madrid, Espasa, 2010, pp. 295296. ZIRIKATU: Komando Autonomoak..., pp. 79-85. 
enero de 1977 un comando mili intentó asesinarlo en Las Arenas, pero el atentado fracasó: tras los cinco primeros disparos, el arma del pistolero etarra se encasquilló ${ }^{37}$.

El primer "judas" oficialmente ajusticiado por la organización fue Ignacio Olaiz Michelena. Camionero en paro y miembro destacado de la Gestora pro amnistía de Andoain (Guipúzcoa), había solicitado su entrada en ETAm. Fue asesinado en octubre de 1978. Su cadáver presentaba diez orificios de bala y tenía billetes de mil pesetas en su mano izquierda, simbolizando así su condición de mercenario a sueldo del enemigo "español". Los milis declararon que la militancia de Olaiz en la "izquierda abertzale" era "una simple tapadera para ocultar su objetivo en infiltrarse en los sectores políticos más combativos de nuestro pueblo y especialmente en ETA para destruirlos". Síntoma de hasta qué punto una parte de la sociedad vasca había interiorizado el discurso ultranacionalista, su viuda se limitó a negar los cargos que se imputaban a la víctima: "no puedo admitir que Euskadi crea eso (...). Era un euskaldun que amaba a Euskadi" 38 .

El segundo suceso fue, quizá, más revelador. Joaquín Azaola Martínez (Jokin) había sido miembro del comando etarra que en 1974 pretendió raptar al entonces príncipe Juan Carlos de Borbón y su familia en la Costa Azul. La intención de la banda era exigir entre 200 y 300 millones de pesetas como rescate, así como la liberación de un centenar de sus presos. Azaola, según confesó en una extensa entrevista al semanario Interviú, estaba convencido de que Franco nunca accedería a tal trato, por lo que el desenlace inevitable era que "hubiéramos tenido que matarlos a todos; una vez comenzada la acción no podíamos echarnos atrás". La consecuencia, dedujo, sería cortar "toda posibilidad de evolución hacia la democracia, hubiera habido un cambio radical a la derecha y una represión horrible contra el pueblo vasco". Sus problemas de conciencia le llevaron a pactar con el enemigo: a cambio de que nadie fuera detenido ni se les imputara luego ningún cargo, Jokin facilitó los detalles del plan a las autoridades españolas, que hicieron fracasar el secuestro. La banda tenía sus sospechas, pero carecía de pruebas. Azaola, acogiéndose a la amnistía de 1977, retomó su vida civil en Guecho (Vizcaya). Los fantasmas de su pasado parecían felizmente enterrados, pero él mismo se encargó de sacarlos a la luz en 1978 al publicar Los elegidos de Euskadi, un libro en el que narraba los pormenores de la frustrada "Operación Pesca". Escribía bajo el seudónimo de Odei Erreka, pero sus antiguos camaradas no tardaron en atar cabos y descubrir quién era el autor de la obra, ergo, quién les había traicionado en 1974. En diciembre de 1978 los milis acabaron con su vida. El comunicado posterior evidenciaba el propósito didáctico de la banda: "Esperemos que la ejecución de Jokin sirva de ejemplo y aviso para quienes se sientan tentados de seguir su camino en la creencia de que ETA no tiene medios de hacer justicia" 39 .

En mayo de 1978 la policía desarticuló un par de comandos de ETAm, uno de cuyos responsables, Tomás Sulibarria Goitia (Tomi), logró huir a Francia. El 30 de agosto sus correligionarios le dispararon en el cuello. Se le acusaba de "haber traicio-

37 El País, Diario 16 y Ya, 12-I-1977.

38 Egin, 31-X, y 1-XI-1978.

39 Interviú, 11 al 17-V-1978, Pueblo 21-XII-1977, y Egin, 21-XII-1978. AZAOLA MARTÍNEZ, Joaquín (Erreka Odei): Los elegidos de Euzkadi. Un atentado al futuro, San Sebastián, Geu, 1977. ALONSO, Rogelio, DOMÍNGUEZ IRIBARREN, Florencio y GARCÍA, Marcos: Vidas rotas ..., pp. 167-169. 
nado a la organización" no solo delatando a sus compañeros, sino también colaborando posteriormente con "los servicios de seguridad españoles" en el atentado contra Juan José Etxabe en el que había muerto la mujer de éste. ETAm confirmó que había otros "infiltrados" en la "izquierda abertzale" a los que advertía: "en la mayoría de los casos conocemos su identidad y que si no abandonan sus intentos de aproximarse a ETA, así como el territorio de Euskadi, nos veremos obligador a actuar contra ellos al igual que lo hemos hecho contra Tomi". Aunque malherido, en aquella ocasión Sulibarria escapó de su fatal destino. En el hospital todavía mantenía que "no es cierto lo que dicen y que pase lo que pase sigo fiel con mi pueblo y mi compromiso". Detenido, pasó un año en prisión. En marzo de 1980 salió en libertad. En junio fue abatido de un tiro en la nuca en Bilbao ${ }^{40}$.

José Luis Oliva Hernández era miembro del comando Orbaiceta de ETAm, que había atracado un banco. Sus camaradas lo declararon culpable de robo: se había quedado con parte del botín para gastarlo con fines personales. Se lo condenó a muerte, sentencia ejecutada el 14 de enero de 1981. Ahora bien, la banda alegó que a Oliva se le había "ajusticiado por infiltración". Incluso en la traición hay grados. La "izquierda abertzale" ya se había acostumbrado a la idea de que ETA podía esconder en su seno a topos de la policía, pero probablemente no se hubiera asumido tan fácilmente que uno de sus heroicos gudaris fuera un vulgar ladrón ${ }^{41}$.

\section{Desertores. ETAm II}

Los crímenes relatados en el apartado anterior se concentran en la Transición, convulso periodo en el que ETAm tenía que competir con otras organizaciones (ETApm y los CAA). Los dos "ajusticiamientos" posteriores respondían a unas circunstancias y una lógica bien diferentes ${ }^{42}$. El Gobierno del PSOE (1982), animado por los resultados positivos de la reinserción de los séptimos, tanteó a HB para que jugase con los milis un papel mediador similar al que había tenido EE con ETApm. La coalición ultranacionalista se negó, ya que, desde su punto de vista, hubiese supuesto una ilegítima usurpación del protagonismo de la banda terrorista, que no estaba por la labor de disolverse. Para sortear dicho escollo el gabinete de Felipe Gonzalez experimentó con una nueva vía: la reinserción individual. A decir de Izaskun Sáez de la Fuente, la contingencia de que cada etarra pudiera acogerse a las medidas de gracia motu propio generó en el nacionalismo radical "la preocupación por su debilitamiento ideológico, ético y social al compás de una opinión pública tendencialmente favorable a la

\footnotetext{
40 Egin, 31-VIII y 1,3 y 5-IX-1978, y 4-VI-1980, y $A B C, 5$-X-1979. ALONSO, Rogelio, DOMÍNGUEZ IRIBARREN, Florencio y GARCÍA, Marcos: Vidas rotas ..., pp. 293-294.

41 Egin, 15-I-1981. ALONSO, Rogelio, DOMÍNGUEZ IRIBARREN, Florencio y GARCÍA, Marcos: Vidas rotas..., pp. 351-352.

42 Según José Luis Barbería, hubo un tercer etarra reinsertado que se salvó de la muerte "porque contuvo su primer impulso de acercarse a saludar a la persona encargada de matarle, una chica, también exiliada, a la que conocía del otro lado. En el crucial momento descubrió que la mujer que esperaba frente al portal de su casa extraía un revólver de su bolso y no estaba sola" (El País, 24-XI-1986).
} 
medida"43. El temor a una deserción masiva en sus propias filas hizo que ETAm cerrara aquella salida de un sangriento portazo.

Miguel Francisco Solaun Angulo, detenido en 1969, fue quien organizó la célebre fuga de la cárcel de Basauri de 1970, que le permitió escapar junto a otros catorce etarras. Regresó del exilio en 1977 al beneficiarse de la amnistía general. Gerente de una constructora, se encargó de la edificación de un grupo viviendas en Algorta (Vizcaya) que luego fue vendido al Gobierno para incorporarlo a la futura casa-cuartel de la Guardia Civil. En 1981 ETAm coaccionó a Solaun para que colocara una bomba de cincuenta kilogramos en su interior, con vistas a un atentado indiscriminado para el día de la inauguración. "Fui conminado por ETA a colaborar y prestar toda la ayuda que me pidieron y me exigieron, so pena de aparecer como un traidor ante ellos y correr la suerte que tuvieron mis amigos", confesaba en una carta personal que salió a la luz tras su asesinato. No obstante, Solaun no conectó los explosivos al sistema eléctrico "porque no soy un asesino". Por añadidura, hizo una llamada anónima avisando a la policía, aunque los artificieros no dieron con el artefacto. No tuvo más remedio que indicar personalmente el paradero exacto. Los miembros del comando responsable y él mismo fueron detenidos. Acusado de colaborar con ETAm, fue condenado a cuatro años de prisión. Allí los presos milis le dieron una paliza, advirtiéndole que no iban a parar hasta "llegar al final". La cosa no fue a mayores porque la comuna $p o-$ limili decidió protegerlo. Gracias a la mediación del parlamentario de EE Juan Mari Bandrés, Solaun fue indultado en 1983. Desde entonces, como se relata en Vidas rotas, "pasó a vivir semioculto por motivos de seguridad, mientras buscaba trabajo fuera del País Vasco". El 4 de febrero de 1984, estando con su familia en una cafetería de Algorta, un joven pistolero le pegó un tiro por la espalda. ETAm reivindicó el atentado calificando a la víctima de "traidor y colaborador de la policía". Se trataba de "una advertencia para todos aquellos que buscan una salida personal a su situación". En su funeral, al que asistieron más de 500 personas, hubo una nutrida representación de euskadikos y séptimos reinsertados. En 1985 los etarras Juan Manuel Piriz y Juan Manuel González fueron juzgados y condenados como autores materiales del asesinato de Solaun. Cuando se les preguntó por qué lo habían hecho respondieron que "todo traidor en una guerra debe ser ejecutado". En el exterior del juzgado, rezaba la crónica de El País, los familiares y amigos de los acusados coreaban himnos nacionalistas y daban goras (vivas) a ETA militar ${ }^{44}$.

Dolores González Katarain (Yoyes) fue la primera mujer que perteneció a la dirección de ETAm, siendo estrecha colaboradora de su principal líder, José Miguel Beñaran (Argala). Tras el asesinato de su mentor a manos de un grupo parapolicial en 1978 se desvinculó de la banda y emigró a México, donde estudió, trabajó y formó una familia. En 1985 regresó a España. Eugenio Etxebeste (Antxon), líder mili refugiado en Santo Domingo, afirmó en un mensaje grabado para la militancia etarra que, al conocer la noticia, había sentido "el pozo sin fondo donde había caído una persona que en vida se llamó Yoyes". Y es que "la vida sintética de la 'Señora Dolores' significa la

43 SÁEZ DE LA FUENTE, Izaskun: "La opinión pública vasca ante la violencia de ETA. Una mirada retrospectiva", Escuela de Paz Bakeaz 23 (2011), p. 10.

44 El País, 5, 6 y 7-II-1984 y 13-III-1985y Zuzen, no 41, I-1985. ALONSO, Rogelio, DOMÍNGUEZ IRIBARREN, Florencio y GARCÍA, Marcos: Vidas rotas..., pp. 467-468. 
muerte de la abertzale Yoyes". La primera, "el nuevo ser que come y respira" no era "más que un producto inanimado de la ciencia política imperialista, un ente artificial movido a control remoto, que voluntariamente prestó su cuerpo para el ejercicio de la experimentación represiva". Su "máximo castigo habrá de llegarle si antes no actúa la violencia revolucionaria, el día en que su hijo le arroje a su propia cara el desprecio de su traición". El colectivo de presos de ETAm la juzgó y condenó a muerte por "traición". Aparecieron pintadas amenazantes en las que incluso se le acusaba de ser una "chivata". A pesar del ambiente hostil, rechazó la protección policial que se le había ofrecido. El 10 de septiembre de 1986 Yoyes paseaba con su hijo por las calles de Ordicia cuando el mili Antonio López Ruiz (Kubati) se acercó a ella: "Soy de ETA y vengo a ejecutarte", anunció antes de asesinarla. Una vez más, los séptimos reinsertados reaparecieron públicamente para manifestarse contra el terrorismo ${ }^{45}$.

Pese a lo que entonces se dijo, González Katarain no se había acogido a la reinserción, ya que no lo necesitaba: carecía de causas pendientes gracias a Ley de amnistía de 1977. En realidad, al retornar de su voluntario exilio mejicano no hizo nada distinto de lo que desde 1976 habían hecho cientos de exetarras. Tampoco era cierto que, como se le imputaba, hubiese optado por "el peor de los caminos, el arrepentimiento, la traición y la colaboración política con los enemigos del pueblo vasco". No hubo tal. Se trataba de una simple excusa. Entonces, ¿cuál fue la auténtica motivación de este crimen? Por un lado, Yoyes, dado el alto cargo que había ocupado en la banda, era una figura simbólica de primer orden. En ese sentido, el dirigente de HB Iñaki Aldekoa justificó el atentado aduciendo que "cualquier ejército del mundo en un estado de confrontación no puede permitirse que uno de sus jefes de Estado Mayor aparezca paseando por territorio ocupado por el ejército contrario". Entre otras cosas, porque demostraría que no había guerra alguna. Por otro lado, la cúpula etarra no le había dado permiso para volver a casa, por lo que su decisión fue interpretada como un desafío. Por último, a decir de Florencio Domínguez, el asesinato respondía al "afán de ETA de impedir que el caso de Dolores González se convirtiera en un ejemplo para otros muchos activistas. La presencia de Yoyes en libertad, haciendo su vida personal y familiar en Guipúzcoa, era una carga de profundidad para la imagen de estado de guerra" de la que se nutría el ultranacionalismo. Así pues, aquella muerte "provocó el efecto de trasladar un mensaje de intimidación a todos los miembros de ETA de cara al futuro". Efectivamente, la amenaza de eliminación física abortó la reinserción. El terror se demostró como un mecanismo de control interno extremadamente eficaz ${ }^{46}$.

45 Transcripción de un mensaje grabado por Antxon desde Santo Domingo, documento incautado a ETA en el zulo de Mouguerre en septiembre de 1994 (cortesía de Florencio Domínguez). El Diario Vasco, 18-IX-1986, El País, 21-IX-1986 y Diario 16, 21-XII-1988. ALONSO, Rogelio, DOMÍNGUEZ IRIBARREN, Florencio y GARCÍA, Marcos: Vidas rotas..., pp. 590-592. Su historia ha sido recogida en el largometraje Yoyes (Helena Taberna, 2000).

46 DOMÍNGUEZ IRIBARREN, Florencio: Dentro de ETA..., pp. 287-288. El País, 3-IV-1987, y Egin, 26-V-1987. 


\section{Conclusiones}

A lo largo de su larga historia ETA y el nacionalismo vasco radical han clasificado a diversos individuos o colectivos como traidores a causa de sus discrepancias ideológicas, el abandono de las armas o la colaboración con las autoridades. En todos estos casos, como señala Mikel Azurmendi, se consideraba que se habían pasado al enemigo secular de Euskadi, esto es, a España, por lo que dejaban de ser vascos genuinos para mutar en "españolistas" o sencillamente "españoles" ${ }^{47}$. En otras palabras, aquellos traidores habían cambiado su propia identidad por la peor imaginable. Lesa patria, la patria quedaba herida. Para curarla, para restaurar el orden natural de las cosas, los renegados debían pagar sus abyectos crímenes. Y no de cualquier manera, sino con castigos ejemplarizantes que cortasen de raíz la reproducción del fenómeno: estigmatización, exclusión social, ostracismo, violencia verbal y física y, en último extremo, el asesinato. Literalmente, la letra con sangre entra. A fin de cuentas, el terrorismo consiste en acabar con la vida de una persona para que otras mil tengan miedo. Únicamente así se podría mantener la disciplina y la cohesión del colectivo, acabar con la iniciativa individual, intimidar a la militancia y acallar al disidente.

Y funcionó. Para comprender hasta qué punto la didáctica del miedo fue útil basta con comparar la rígida, jerárquica y militarizada unanimidad de la "izquierda abertzale" tradicional con los debates horizontales y las múltiples desavenencias habidos en EE. La disciplina se mantuvo en ETAm, al menos hasta la captura de su cúpula en Bidart (1992), pero, pese a que no hubo "ejecuciones" en su seno, el terror también obró su efecto en la rama civil del movimiento ultranacionalista. Tal y como mantiene Mikel Arriaga, en HB "la formalización de heterodoxias colectivas" no encontró "viabilidad, momento y espacio de negociación", ya que "cuando excepcionalmente afloran brotes individuales o minoritarios de heterodoxia activa son arrancados de raíz, arrojados a la orilla y fugazmente distanciados y perdidos de vista". El caso más conocido fue el de Txomin Ziluaga, quien desde 1978 ocupaba la secretaría general de HASI, Herriko Alderdi Sozialista Iraultzailea (Partido Socialista Revolucionario del Pueblo), formación sobre la que pivotaba la coalición abertzale. En 1987, tras el atentado indiscriminado en el centro comercial Hipercor de Barcelona que costó la vida a 21 personas, sugirió a la banda que se tomara "unos meses de vacaciones". Como escarmiento, los milis decretaron que Ziluaga fuera destituido de su cargo y después expulsado de HASI. Le acompañaron muchos de sus partidarios, pero procuraron no molestar a los etarras. A decir de Florencio Domínguez, ETAm "les obligó a mantenerse en silencio, sin hacer públicas las circunstancias en que se había desarrollado la crisis. La mitad de los militantes abandonaron el partido, sin que ninguno de ellos dijera esta boca es mía o se planteara organizar otra formación" 48 . Sabían muy bien lo que les esperaba de haberse atrevido a hacerlo. De hecho, en la "izquierda abertzale" no hubo ninguna disidencia significativa hasta la aparición de la corriente crítica Aralar, dirigida por Patxi Zabaleta, que se escindió para conformar su propio

47 AZURMENDI, Mikel (1994): "Etnicidad y violencia en el suelo vasco", en FERNÁNDEZ DE ROTA, José Antonio FERNÁNDEZ (ed.): Etnicidad y violencia, La Coruña, Universidad de La Coruña, 1994 , p. 95.

48 ARRIAGA, Mikel: ... y nosotros..., p. 210. DOMÍNGUEZ IRIBARREN, Florencio: Josu Ternera. Una vida en ETA, Madrid, La esfera de los libros, 2006, pp. 146-149. 
partido en 2001. Ese colectivo sufrió presiones y amenazas tanto cuando estaba dentro como ya fuera del nacionalismo radical ligado a ETAm. La historia se repetía.

Además de lo descrito, la persecución de los "traidores" cumple otra labor que conviene destacar: la animadversión a los "otros" une sacramentalmente al "nosotros". Como señalaba Eric Hoffer, si bien los colectivos políticos cuentan con numerosos "agentes unificadores", hay uno que los supera a todos: "el odio es el más accesible y el de mayor alcance", ya que "extrae y hace girar al individuo fuera de su propio yo, lo hace olvidar su bienestar y su futuro, lo libera de envidias y del deseo de buscar algo para sí mismo. Lo transforma en una partícula anónima estremecida por el anhelo de confundirse y coaligarse con sus similares en una masa apasionada". En definitiva, "un movimiento de masas puede surgir y extenderse sin creer en un Dios, pero nunca sin creer en un demonio". En ese sentido, pese a que España continuó siendo su némesis, a partir de los años sesenta la "izquierda abertzale" vio, trató e instrumentalizó como su particular Satán a ETA berri, ETA VI, ETApm, EE y los milis infiltrados o reinsertados. Al fin y al cabo, al igual que los traidores en el imaginario ultranacionalista, Lucifer era un ángel caído ${ }^{49}$.

\section{Referencias bibliográficas}

ALONSO, Rogelio, DOMÍNGUEZ IRIBARREN, Florencio y GARCÍA, Marcos: Vidas rotas. Historia de los hombres, mujeres y niños víctimas de ETA, Madrid, Espasa, 2010.

ARRIAGA, Mikel: ...y nosotros que éramos de HB... Sociología de una heterodoxia abertzale, San Sebastián, Haranburu, 1997.

AZAOLA MARTÍNEZ, Joaquín (Erreka Odei): Los elegidos de Euzkadi. Un atentado al futuro, San Sebastián, Geu, 1977.

AZURMENDI, Mikel (1994): "Etnicidad y violencia en el suelo vasco", en FERNÁNDEZ DE ROTA, en José Antonio FERNÁNDEZ (ed.): Etnicidad y violencia, La Coruña, Universidad de La Coruña, 1994, pp. 77-100.

CASQUETE, Jesús: En el nombre de Euskal Herria. La religión política del nacionalismo vasco radical, Madrid, Tecnos, 2009.

DOMÍNGUEZ IRIBARREN, Florencio: Dentro de ETA. La vida diaria de los terroristas, Madrid, Aguilar, 2002.

DOMÍNGUEZ IRIBARREN, Florencio: Josu Ternera. Una vida en ETA, Madrid, La esfera de los libros, 2006.

EGAÑA SEVILLA, Iñaki: Diccionario histórico-politico de Euskal Herria, Tafalla, Txalaparta, 1996.

EGIDO, José Antonio: Viaje a la nada. Principio y fin de Euskadiko Ezkerra, Tafalla, Txalaparta, 1993.

ELORZA, Antonio: La religión política. "El nacionalismo sabiniano" y otros ensayos sobre nacionalismo e integrismo, San Sebastián, R\&B, 1995.

49 HOFFER, Eric: El fanático sincero, México DF, Libreros Mexicanos Unidos, 1964, p. 129. 
ESCRIVÁ, María Ángeles: El camino de vuelta. La larga marcha de los reinsertados en ETA, Madrid, El País Aguilar, 1998.

ESTORNES ZUBIZARRETA, Idoia: “Abandonando la casa del padre. Eusko Langileen Alkartasuna-Solidaridad de Trabajadores Vascos (Movimiento Socialista de Euskadi), 1964-1969", Historia Contemporánea, 40 (2010), pp. 127-159.

FERNÁNDEZ SOLDEVILLA, Gaizka: Héroes, heterodoxos y traidores. Historia de Euskadiko Ezkerra (1974-1994), Madrid, Tecnos, 2013.

FERNÁNDEZ SOLDEVILLA, Gaizka y LÓPEZ ROMO, Raúl: Sangre, votos, manifestaciones. ETA y el nacionalismo vasco radical (1958-2011), Madrid, Tecnos, 2012.

GARMENDIA, José María: Historia de ETA, San Sebastián, Haranburu, 1996 (1ª ed. 19791980).

HOFFER, Eric: El fanático sincero, México DF, Libreros Mexicanos Unidos, 1964.

HORDAGO, Equipo: Documentos Y, San Sebastián, Hordago, 1979-1981, 18 vols.

IDÍGORAS, Jon: El hijo de Juanita Gerrikabeitia, Tafalla, Txalaparta, 2000.

JÁUREGUI, Gurutz: Ideología y estrategia política de ETA. Análisis de su evolución entre 1959 y 1968, Madrid, Siglo XXI, 1985 (1 $1^{\mathrm{a}}$ ed. 1981).

JÁUREGUI, Gurutz: Entre la tragedia y la esperanza. Vasconia ante el nuevo milenio, Barcelona, Ariel, 1997.

KRUTWIG, Federico: Vasconia, Pamplona, Herritar Berri, 2006 (1 $1^{\mathrm{a}}$ ed.: 1963).

LEVINGER, Matthew y LYTLE, Paula Franklin: "Myth and mobilisation: the triadic structure of nationalist rhetoric", Nations and Nationalism, 7 (2001), pp. 175-194.

MOVIMIENTO VASCO DE LIBERACIÓN NACIONAL: "Euskadi en guerra. Un horizonte para la paz”, en VVAA: Euskadi en guerra, Bayona, Ekin, 1987, pp. 223-264.

ONAINDIA, Mario: Carta abierta sobre los perjuicios que acarrean los prejuicios nacionalistas, Barcelona, Península, 1995.

PABLO, Santiago de y OTROS: Diccionario ilustrado de símbolos del nacionalismo vasco, Madrid, Tecnos, 2012.

RAMÍREZ, Pedro J.: La rosa y el capullo. Cara y cruz del felipismo, Barcelona, Planeta, 1989.

SÁEZ DE LA FUENTE, Izaskun: "La opinión pública vasca ante la violencia de ETA. Una mirada retrospectiva", Escuela de Paz Bakeaz 23 (2011).

UNZUETA, José Luis: “La V Asamblea de ETA”, Saioak, 4 (1980), pp. 3-52.

UNZUETA, José Luis: Los nietos de la ira. Nacionalismo y violencia en el País Vasco, Madrid, El País Aguilar, 1988.

URIARTE, Eduardo: Mirando atrás. Del proceso de Burgos a la amenaza permanente, Barcelona, Ediciones B, 2005.

VINADER, Xavier: Operación Lobo. Memorias de un infiltrado en ETA, Madrid, Temas de hoy, 1999.

VOLTAIRE: Tratado sobre la tolerancia, Barcelona, Público, 2010 [1 ${ }^{\mathrm{a}}$ ed. 1767].

ZIRIKATU: Komando Autonomoak: sasiaren arantzakada. Una historia anticapitalista, Bilbao, Felix Likiniano, 1999. 